\title{
Research of Tender Control Price in Oil and Gas Drilling Engineering Based on the Perspective of Two-Part Tariff
}

\author{
Xiaohao Zhou ${ }^{1, a}$, Chunfa $\mathrm{Li}^{1, \mathrm{a}}$ and Mingying Dong ${ }^{1, \mathrm{~b}}$ \\ ${ }^{1}$ School of Management, Tianjin University of Technology, Tianjin, China \\ axiaohaozhou@126.com, ${ }^{\mathrm{b}}$ mydong0317@163.com
}

Keywords: Oil and gas drilling engineering, Two-part tariff, Bill of quantities, Tender control price

\begin{abstract}
Determine the tender control price reasonable is not only the key to the success of bidding work, but also the first step of consummate the market pricing. In view of the establishment of tender control price in force lack of accuracy, this paper build the oil and gas drilling engineering tender control price model in the perspective of two-part tariff ideology. We make bill of quantities, geological conditions and environmental protection investment as the project construction cost into fixed fee, make the cost of labor and materials, which under the advanced social average level, as the fee to encourage enterprises improve their technology management into variable fee. Meanwhile, select two indicators, the consumer price index and international crude oil price, reflect the price change. Provide a reference for complete the establishment of oil and gas drilling engineering tender control price and improve the forecast accuracy of the project investment.
\end{abstract}

\section{Introduction}

Oil and gas drilling project contracting activities put bidding system into practice, tendering stage will directly affect the project cost from the effective date to completion settlement period. Tender control price is a highest price of engineering in the preparation of the bidding stage, reflect the social average level, too high or too low are detrimental to the tender. Its setting can reduce the occurrence of unbalanced quotation, improve the transparency of the bidding activities, specification the order of construction market, guide the behavior of the main construction, make the employer control the project investment in advance and provide reference for cost control in the implementation stage. So, determine the tender control price reasonable is not only the key to the success of bidding work, but also the first step of consummate the market pricing.

The future development trend of oil and gas drilling engineering technical service market will be marketization, the oil and gas drilling industry has been fully implementing the bill of quantities valuation pattern, but has not formed its special specification calculation of engineering quantity and project measurement standard system. Oil and gas drilling is an underground engineering which has strong organizational, intensive technology, big risk and large difference of professional engineering, has bigger difference in the market environment and construction characteristics with the general construction project. Completely copy bill of quantities valuation mode due to the oil and gas companies valuation methods different, makes the compilation of oil and gas drilling engineering tender control price more unreasonable.

In preparation of foundation, oil and gas drilling industry has not yet been formulated special specification calculation of engineering quantity and project measurement standard system, unable fully applying bill of quantities for construction project in view of its construction characteristics, companies has big difference in project divided, easy to appear error such as missing items, that caused the accuracy and completeness of the list. In compilation basis, the price of labor, materials and mechanical which engineering cost management agencies released is hysteresis, does not reflect the engineering practice value. With the development of technology and labor productivity rise ceaselessly, the valuation quota issued by the competent department of construction of national, provincial or industry, failed to update, caused many new technology without quota, the existing quota lack of timeliness and not considering geology, national policy and the market price changes[1], 
traditional quota is increasingly difficult to meet the demand of engineering practice. In market environment, bill of quantities is suitable for the perfect competition market environment, while the oil and gas drilling industry is related party transactions and market competition. In the future, oil and gas companies will fully expand the cooperation with society, private and foreign capital, and the associated enterprises because of the influence of the traditional connection transaction mode disadvantages, is relatively backward in the reform and innovation, personnel management and technology development, has disadvantages in short term market competition. So completely adopted to bill of quantities is bad for the group's overall profit maximization.

\section{Application Analysis}

Oil and gas is a typical natural monopoly industry in our country, while two-part tariff is a pricing method which generally used in natural monopoly industry, its essence is a combination of quota and quantity charge. With the deepening of the research, its application form is non-uniqueness, application scope is not confined to the traditional product pricing, various industries can implementing the difference charge according to its own characteristics, it began to widely used in transportation, telecommunications, garbage disposal, tuition Internet platform pricing and so on[2]. As a construction product, the influence factors of oil and gas drilling engineering tender control price can be divided into fixed fee and variable fee, make the price reflect the engineering characteristics and market price, more reasonable and accuracy.Previous analyses the cost factors from various angles, such as Y. Zou[3]detailed analysis the process of drilling and established the drilling process cost model that suitable for budget phase. T. Wang[4] analysis the affecting factors from the aspects of technology, macro and micro, then put forward the related efficiency measures. Y.J Zhang[5] analysis the risk factors that influence the engineering cost from the aspects of natural and technology. These studies laid the foundation of identified and classified influence factors and build two pricing model.

As a kind of construction products, drilling engineering cannot batch production like the general industrial product, so the classified methods need to be adjusted. From the angle of charging purpose, fixed fees charged by the enterprises make up the public cost, help to normal operation, variable fees charge in order to encourage enterprises to raise the level of output, so as to improve the level of social welfare. To this end, oil and gas drilling engineering tender control price may be implement two department of pricing considered project characteristics. According to the charging purpose, define project construction cost as a fixed fee, define the cost that encourage enterprises to improve their management level as a variable fee.

Reference to previous research results, this article consider economy, technology, management, policy and natural as the oil and gas drilling engineering cost factors. Economic factors mainly embodied in price fluctuations of wages and material, technology and management factors affect consumption, policy factors mainly consider national security environmental protection requirements for engineering. In addition, oil and gas drilling engineering is the underground project, cannot ignore the influence of geological conditions on the engineering cost. So this article according to the characteristics of oil and gas drilling engineering, on the basis of current tender control price, considering drilling engineering cost influence factors and two-part tariff cost classification definition, division the oil and gas drilling engineering tender control price cost.This kind of method to determine the tender price control made up for the shortcomings of the existing establishment method, closer to the engineering practice value, incentive associated enterprises improve their management technology level and realize the profit maximization of whole enterprise.

\section{Model Building}

Fixed Fee. Although the bill of quantities pricing mode is restricted by many factors in the process of application in oil and gas drilling engineering, but as the market gradually open and the continuous improvement of this valuation method, this kind of pricing mode will become the mainstream of 
engineering cost management in our country, cause it is the optimal project in line with international standards and market rules, so this article on the basis of its improvement.

Oil and gas exploration is currently faced with many severe challenges, such as the inferior resources quality, the complex target, the security environmental protection strictly and so on, the resources grade and environmental protection policy more and more obvious impact on drilling engineering price. The valuation reflect a kind of general situation, not consider the geology and the influence of national policy when making the valuation quota, so we need to consider the influence of these two factors when pricing.

Oil and gas exploration and development project has certain environmental risk, construction units must develop a stringent environmental protection measures for some environmental factors such as oil and gas leakage or "three wastes" emissions. The companies will increase production process hazard prevention and environmental protection regulation, increase the intensity of environmental sensitive area ecological restoration, actively promote the development and utilization of clean energy and environment friendly products, environmental damage compensation will be more stringent after the new environmental protection law published. This means that the construction units will increase environmental investment, strengthen the environmental protection measures to achieve sustainable development. One of the important measures to realize the sustainable development is accounting the resource consumption and environmental impact into the cost. R.Z. $\mathrm{Du}[6]$ in the case of oil product pricing mechanism, make the marginal environmental cost as a part of the fixed fee to determine monopoly resource prices. Inspired by this, when determining oil and gas drilling project tender control price, company can also according to the time series environmental project investment and the state environmental protection policy, to predict the increase of "three simultaneity" environmental protection investment and recorded in the fixed fee.

The drilling engineering belongs to the underground engineering, geological environment is fuzziness and uncertainty, easily to change the drilling cost. The current global exploration and development are development from the conventional reservoir to low permeability and unconventional, the domestic resources to be developed are mainly concentrated in the deep low permeable reservoirs, marine oil and gas reservoirs and unconventional reservoirs. The worse the resources grade, the higher the requirement of engineering technology, engineering cost also higher. In view of this, the oil and gas drilling companies can according to the history data, on the basis of the valuation costs, set all kinds of coefficient to reflect the influence of geological conditions on the engineering cost.

Considering the above factors, the fixed cost is expressed as:

$$
F C=(1+\alpha) Q+E .
$$

In the formula, $Q$ as the price of the valuation, $\alpha$ as the increase costs coefficient by resources grade, $E$ as the increase investment in environmental protection.

Variable Fee. The progress of engineering technology and management level driving construction quota consumption reduced. To encourage enterprises improve their technology and management level, this paper choose the social average advanced level of consumption as the used consumption when price adjustment, thus we can promote the efficient allocation of resources and incentive enterprises at the same time through the leverage of price. Especially incentive associated business enterprises continuously improve their production efficiency in order to gain more profit, realize the maximization of resources allocation and overall profit, enhance the competitiveness of the group, has the ability to participate in market competition as early as possible. Given the valuation quota and industry cost information used to make the tender control price has the objective of hysteresis, and economic factors such as rising prices will affect the labor and material cost fluctuation, causing the deviation of investment. So we should be reasonable predict the evolution of the wages and material price when determining the tender control price.

The wages can be expressed in labor price index for reflect the construction period price daily changes. T. Li[7] in the case of power industry, reference price regulation model which commonly used in developed countries, based on the current production costs, use the consumer price index and 
producer price index as two price changes indicators, respectively represent how the price changes of wages and raw material influence the cost of production. She uses the natural monopoly enterprise's actual cost to replace social costs, to reflect the market influence on prices, this kind of ideas worth using for reference.

The artificial unit price of construction and installation workers must belongs to the social average, while the social average wage level will depend on the economic development, and consumption index will also affect the changes. So we can consider the consumer price index and GDP index as linkage factors for analysis the artificial cost price index, then forecast the change of labor in the project construction period. Regardless of the changes in consumption, the change of daily wages in construction period is expressed as:

$$
\Delta P_{1}=P_{n}-P_{0}=P_{0}\left(\beta_{1}-1\right) \text {. }
$$

In the formula, $P_{0}$ as the base rate of daily wages, $\beta_{1}$ as the prediction results of artificial cost price index in the project construction period.

From the perspective of the materials cost, oil and gas drilling engineering materials and tools cost mainly composed by diesel, tube stock, cement and so on. Studies have shown that diesel and tube stock is the main consumption, among them, diesel cost occupy 26 percent of raw materials cost, 8 percent of the whole drilling cost. Tube stock basic manufactured by steel, the steel price changes will affect the price of related drilling equipment and facilities. Therefore, only grasp the prices variation rule of diesel and steel can better predict the cost of materials, at the same time provide strategy to control the drilling cost. F.J An[8] in case of the United States drilling market, use multiresolution wavelet analysis to study the dynamic relationship between diesel, steel and crude oil price. Results show that the three has significant correlation and synchronicity on different cycle, has the price conduction phenomenon, and crude oil price fluctuations more dramatic then diesel and steel, means we can forecast diesel and steel price changes according to the crude oil price. The United States as the world's largest oil consumer, its drilling cost structure is representative, the analysis results can be partly reflect the situation of China. So this article choose the international price of crude oil for indicators to reflect diesel prices $P_{2}$, choose fluctuations in steel prices $P_{3}$ to reflect tube stock prices changes, then forecast material cost changes in project construction period.

Considering the above factors, the variable cost is expressed as:

$$
Q C=P_{0}\left(\beta_{1}-1\right) \Delta X_{1}+\Delta P_{2} \Delta X_{2}+\Delta P_{3} \Delta X_{3} \gamma \text {. }
$$

In the formula, $\Delta X_{1} \Delta X_{2} \Delta X_{3}$ as oil and gas company determine the average consumption of labor, diesel and steel in accordance with the social average advanced level. $\Delta P_{2} \Delta P_{3}$ as the fluctuation of diesel and steel prices, they both can be reflected by the international crude oil prices. $\gamma$ as a coefficient of how the steel prices influence average price of all kinds of pipes, the company can determine it according to the required pipe type.

Based on this, we can get the oil and gas drilling engineering tender price control in the perspective of two-part tariff:

$$
P=F C+Q C=(1+\alpha) Q+E+P_{0}\left(\beta_{1}-1\right) \Delta X_{1}+\Delta P_{2} \Delta X_{2}+\Delta P_{3} \Delta X_{3} \gamma .
$$

This model not only has one form, different companies can be decided according to the actual situation, all coefficients can be made by project historical data , national policy requirements, in combination with the practical situation of engineering.

\section{Conclusion}

The two-part tariff model we build to solve the oil and gas drilling engineering tender control price is based on the current compilation method, regard construction cost as fixed fee, regard fees that in order to encourage enterprises improve their management level as variable cost, meanwhile, 
considering geology, environmental protection and social average advanced level of price changes. For ease of calculation, we select two indicators, the consumer price index and international crude oil prices, to reflect the price change of labor and main materials. We suggest in the process of pricing, oil and gas company gradually establish its own database, make all kinds of price influence coefficient conform to the industry characteristics, pay more attention to the consumer price index and international crude oil price trends, timely find relevant indicators change on the influence of drilling investment, lay the foundation of predict accurate project investment and formulate the reasonable oil gas drilling engineering tender control price.

\section{References}

[1] Y. Zhang and J. Peng, Analysis on the hysteretic nature of drilling engineering quota and recommendations for improvement, Value Engineering, 2012, (21), pp. 36-37. (In Chinese)

[2] H.J. Li and H. Yu, The application of telecommunication charges nonlinear pricing in our country, Technology innovation and application, 2014, (8), pp. 251. (In Chinese)

[3] Y. Zou, Drilling cost analysis of oil field productivity construction, Southwest Petroleum University, 2013. (In Chinese)

[4] T. Wang, The influence factors of drilling cost and efficiency measures in petroleum enterprise, Capital University of Economics and Business, 2013, (In Chinese)

[5] Y.J. Zhang and W.J. Zhang, Petroleum drilling engineering project cost risk control research, China Petroleum and Chemical Standard and Quality, 2013, (16), pp. 245. (In Chinese)

[6] R.Z. Du, Research of pricing mechanism in monopoly industries, Southwestern University of Finance and Economics, 2008. (In Chinese)

[7] T. Li, The price regulation research of natural monopoly industries in China, Jinan University, 2011. (In Chinese)

[8] F.J. An, The dynamic relationship between oil drilling cost and industrial development, China University of Geosciences, 2014. (In Chinese) 